\title{
Transition to adulthood for young people with intellectual disability: exploring transition partnerships from the point of view of professionals in school and post-school services
}

Running head: Transition to adulthood

Authors: Maria Pallisera, Montserrat Vilà, Judit Fullana

Institute of Educational Research, University of Girona (Spain)

Correspondence: Maria Pallisera, Institute of Educational Research, University of Girona, C/

St. Domènec, 9, 17071 Girona, Spain. E-mail: maria.pallisera@udg.edu

Keywords: transition to adulthood, intellectual disability, transition partnership

Word count: 6.285

\section{Author note:}

This work was supported by the MINECO (Spanish Public Science Foundation) (grant number EDU2011-22945). The funding bodies have not imposed any restrictions on free access to or publication of the research data.

\section{Ethics}

a) This manuscript is submitted to the JIDD to be considered for publication.

b) The manuscript has not been published elsewhere, is not currently submitted elsewhere and is significantly different from other manuscripts that the authors have submitted elsewhere.

c) The authors state that in each stage of the research the ethical guidelines of the Spanish Psychological Society have been followed. 
d) Information regarding "Conflict of Interest" (which does not exist) is included in the Acknowledgement section.

e) All the authors have contributed to, seen, and approved of the manuscript and agree to the order of authors as listed on the title page.

\title{
Transition to adulthood for young people with intellectual disability: exploring transition partnerships from the point of view of professionals in school and post-school services
}

\begin{abstract}
:
Background Transition partnerships are considered a key factor in fostering transition to adulthood for young people with intellectual disability (ID). The aim of this research was to analyse the transition partnerships between services and projects which support young people with ID in their transition to adulthood from the perspective of the professionals involved.
\end{abstract}

Method Semi-structured interviews were conducted with 45 key professionals from different post-school and school projects, obtaining information regarding the main problems found in coordinating the services, their causes, and suggestions for improvement.

Results A lack of continuity was highlighted in the support for young people with ID during the transition process. Insufficient information and collaboration between services and professionals, and a lack of leadership, were the main problems perceived by professionals.

Conclusions Our research stresses the need to establish clear guidelines to distribute roles and responsibilities of professionals and services involved in the transition. Improving communication processes between professionals and between them and young people and their families is underlined as a way to help young people with ID in their transition. Reinforcing the role of the local area is also recommended. 


\section{Transition to adulthood for young people with intellectual disability: exploring transition partnerships from the point of view of professionals in school and post-school services}

\section{INTRODUCTION}

Research into the processes by which young people with intellectual disability (ID) make the transition to adulthood has been taking place for thirty years. Despite the usefulness of this research, transition still remains one of the most complex challenges facing young people with ID (Beresford, 2004; Hudson, 2006; Kaehne \& Beyer, 2009; Winn \& Hay, 2009).

Transition may be considered a multidimensional process that includes beginning working life, social and community participation, establishing satisfactory adult relationships, and beginning emancipation from the family (Cobb \& Alwell, 2009). Individual transition pathways that lead to the achievement of these objectives are built on the basis of support offered by schools and post-school services. One of the key features of this transition is the existence of a wide range of professionals, agencies, centres or services that can offer support to young people with ID throughout this process. Along this pathway, young people are assessed for the support they need by the different centres or services through which they pass (Foley et al, 2012). The wide range and fragmentation of services that support people with disability in facilitating employment, access to an independent life, training and leisure, is a recurring theme in the research in most developed countries (Hudson, 2003, 2006; Pallisera, 2011; Winn \& Hay, 2009).

In recent years, a commitment to inclusive education has created new challenges when it comes to transition (Kaehne \& Beyer, 2009). 


\section{Transition partnerships: a key element in fostering transition processes for young people with intellectual disability}

Transition partnerships are considered a key factor in fostering transition processes (Barron \& Hassiotis, 2008; Katsiyannis et al, 2005; Kochhar-Bryant \& Greene, 2009). Wehman et al (1988) established three models of inter-agency interaction that reveal the degree of collaboration between transition services. This framework is still considered relevant today as it helps to analyse the system of relationships between organizations working on transition (Kochhar-Bryant \& Greene, 2009). In Model A (Information Transfer), the process involves exchanging information regarding young people. In Model B (Responsibility Transfer), meetings are held between professionals from different services to develop an individual plan for transition before schooling ends. Model C (Collaborative Exchange), represents the greatest degree of collaboration and cooperation between transition personnel and agencies. Here, the various agencies work with the young person in transition, planning the transition process and dividing up responsibilities.

Beyer and colleagues (2008a, 2008b, 2008c) carried out research to determine what processes work in helping young people with the transition from school or college to employment. This research provided interesting results regarding inter-agency coordination and highlighted the need to improve the communication between various school and postschool services. The same conclusions were also reached by Foley et al (2012) and Tarleton and Ward (2005). Beyer and Kaehne (2008) pointed to problems in achieving good coordination between services being mainly due to a lack of collaboration between different professionals, as well as the isolation, fragmentation and duplication of services between different agencies and competition for funding between different services working in the same region. Taylor (2006) also argued that it is difficult to develop effective new partnerships when different employment and education institutions are involved, with 
different goals and sometimes with divergent interests. Hudson (2006) introduced the need for good leadership to foster transition. In this respect, Rush et al (2009) highlighted the leadership role of secondary schools by describing their relevance regarding the provision of adequate training, guiding young people towards desired and appropriate services, and enhancing coordination between services. A substantial number of young people with ID will at some point need support in their transition process. Hence, there is a need to establish continuity in planning transition, and in coordinating efforts between schools and post-school placements (Beyer \& Kaehne, 2008b).

Analysing partnerships between the different institutions involved in transition requires evaluating the suitability of the various services involved. That is, consideration should be given to whether the services that young people with ID can access during the transition process are adequate in meeting their individual needs. From this perspective, it is important to assess the issue of accessibility to post-compulsory education. As highlighted by Katsiyannis et al (2005), the usual dynamic for young people with disabilities consists in focusing their transition process on the search for work and independent living, and as Gregg (2007) points out, young people with ID have difficulties accessing post-secondary education on either a vocational or academic path. We can view the lack of such options as considerably limiting the opportunities young people with ID have in achieving a level of education or training that allows their later inclusion in the labour market.

The importance of establishing clear guidelines for the transition process is widely recommended (Beyer \& Kaehne, 2008c, Tarleton and Ward, 2005). By familiarizing professionals involved in decision-making processes with the range of alternatives available in the different sectors (e.g., social services, health, higher education, leisure, work), this can provide a further necessary element for both families and young people involved in the process: access to suitable information regarding alternatives and future possibilities. Some 
countries implement measures aimed at improving coordination between transition services. Since 1997 all IEPs (Individualized Education Programmes) in the United States include an individualized needs analysis regarding transition from the age of 14 onwards, two years before the end of compulsory education (Rush et al. 2009). In the UK, from Year 9 onwards all young people with ID have the right to an annual transition planning meeting. These meetings are usually held at school and organized by the school's special educational needs co-ordinator (Kaehne, 2012).

Above and beyond the existence of guidelines at the state level, there is also a need to articulate actions on a local level (Kochhar-Bryant \& Greene, 2009). By way of example, Kaehne and Beyer (2008b) point out the role that local employment providers can play at different stages of the transition process, and recommend their inclusion in multidisciplinary working groups involved in the process.

In Spain, where our research was carried out, very few studies have been conducted with the aim of focusing strictly on how transition processes develop towards the desired objectives of inclusion in society and the workplace. From 1990, the General Statutory Act on the Education System (LOGSE, 1990) established compulsory secondary education from the ages of 12 to 16 years. Only in cases where there was reasonable doubt that the needs of the pupils could not be met at a mainstream school is schooling at special educational centres permitted.

Although the Spanish Act on the Social Integration of Disabled Persons (LISMI 1982) has the aim of including people with ID into the general employment system, after completing compulsory schooling the most common step for students with ID is to access one of the services aimed at adults with disability: Special Employment Centres or Occupational Centres (Valls \& Jové, 2001 and Rosselló \& Verger, 2008). The aim of the former is to 
provide users with productive work, offering in exchange remuneration and personal and social adaptation. Occupational Centres provide non-working care for adults who are not considered to be employable. Along with these specific services, there is also a growing number of initiatives designed to foster inclusion in the workplace by means of supported employment.(Becerra, Montanero \& Lucero, 2012; Jordán de Urríes \& Verdugo, 2010).

A previous Spanish study (Pallisera, Vilà \& Fullana, 2012) showed that secondary school does not adequately prepare young people for their future inclusion in the workplace and that no protocols have been established to facilitate information exchange between services when compulsory schooling ends. The lack of consensus on what is meant by social inclusion among school and post-school services is a major problem in the transition process in Spain (Pallisera, 2011).

The aim of the present study is to assess how different Spanish organizations work together to meet the needs of young people with ID during their transition process by analysing the perceptions of the professionals working in those organizations. Any deficiencies these professionals perceive and their proposals for improvement will help to improve transition processes and suggest means of improvement.

\section{METHOD}

The study presented in this paper formed part of a wider body of research aimed at determining the problems and difficulties involved in the transition to adulthood of young Spanish people with ID and proposing measures for improvement (Pallisera, Fullana, Martin \& Vilà, 2013).

\section{Participants:}

Our aim was to select participants who had experience in supporting the transition process of young people with ID and worked in different areas of the Autonomous Region of Catalonia, 
where the study was conducted. In the first phase, we selected 8 local territorial services with the most common types of services that supported young people with ID in their transition (special educational schools, secondary schools, occupational centres, special work centres and supported employment services). A team member then contacted the service by telephone and discussed the purpose of our study with representatives of the organization and requested an interview one or more employees of the service. The relevant service chose one or more people to participate who had direct responsibility for organizing educational or social transition activities. Each participant was asked at the time of the interview if they could recommend an experience/organization which from their perspective represented an example of best practices in transition. Participants were asked this question once they had already considered the current problems of the transition process and contributed suggestions for improvement on different levels (i.e., organizational, curricular, coordination of services and professionals). After suggesting a service or professional, the professionals interviewed were asked to provide arguments for their suggestions, and thus the research group was able to make a selection of new centres and professionals to interview, leading to a second phase of 18 further interviews.

In total, 45 participants were included in the study, all with responsibilities in the transition of young people with ID from school to post-school (see Table 1).

$<$ Please insert Table 1 about here>

Regarding gender, $80 \%$ of participants were female. In terms of professional experience, $64 \%$ had been working in the transition of people with disabilities for more than 15 years, while $33 \%$ had between 8 and 15 years of experience.

\section{Procedures}


The method used to collect information was in-depth interviews. A semi-structured interview was designed to obtain data on two subjects: 1) professionals' view of the current process followed by young people in their transition and 2) professionals' desired view of transition. It was expected that the contrast between the two visions would help us to identify the main problems and provide suggestions for improvement. Open questions were asked in order to assist the professionals to reflect about these subjects. Examples of questions in that interview were: what is your opinion about the service's relationship and coordination with other services from the same sector?, what would you change on the service coordination level in order to build appropriate transition processes?.

Twenty-six interviews were undertaken, 14 individual and 12 group interviews, between February and June 2012. Group interviews were used in the case of organizations with various different services related to transition (e.g., organizations that had school services, job training services, employment services). In these cases, the interviews were conducted in groups to take advantage of different views on the issues. Interviews were conducted at the participants' places of work by 5 members of the research team, working in pairs. The average length of the interviews was 60 minutes for individual interviews, and an hour and a half for group interviews. In accordance with the ethical guidelines of the Spanish Psychological Society, informed consent was sought from participants to record the interviews.

Interviews were carried out at the professionals' places of work, which were located in 9 different cities of the Autonomous Region of Catalonia. The process of conducting interviews was concluded when, through the constant comparison of data (Bowen, 2008), it was found that no new contributions were being made and theoretical saturation was considered to have been reached (Gillham, 2005). 


\section{Data Analysis}

Thematic analysis was followed and initial temporary codes were established based on the interview topics (Miles \& Huberman, 1994). This process allows the codes to be harmonized with the study framework and ensures the analysis meets the objectives of the research. We opted for a combination of structural coding and descriptive coding (Saldaña, 2009). The codes were descriptive in the sense that the basic topic for each piece of data was summarized in a word or short phrase.

The analytical process was as follows: (a) two researchers jointly analysed an interview, taking into account these initial codes and establishing new ones on the basis of the participant's narrative. The list of codes was then reformulated in light of this; (b) using this list, two researchers individually analysed 5 interviews each; (c) the researchers compared their work and agreed on the final codes and definitions. As proposed by Hamilton and Corbett-Whittier (2013), the comparison following the individual work focused on commonality of interpretation as a means of reflecting on any assumptions which had affected the individual analysis and as a way to define the basic codes; (d) all interviews were encoded using the new list of codes, with the help of the Atlas.ti program (Atlas.ti Scientific Software Development, 2012). During the encoding process, the researchers wrote questions, thoughts and ideas; (e) after the first encoding of the interviews, two people from the team performed a second review of the coding and all annotations made before proceeding to the second cycle of encoding, which consisted of grouping those codes that refer to the same subject categories. The following themes developed from this process: the current transition process, theoretical or ideological positioning on transition, working with families, training professionals, the role of the person with disability in the transition process, and transition partnerships. 
In this article we focus on the analysis of information we classified under the theme "transition partnership", which allows us to study the process of coordination between services and professionals working in the field of transition in more depth. Specifically, we established three sub-themes of analysis that were included in the larger theme of transition partnership: coordination between the school and post-school services (examples of codes: continuity of support and coordination of support provided by professionals); perceived problems in coordination between services (e.g., lack of individual transition planning, lack of coordination between school and post-school services, lack of communication between services, lack of leadership); and suggestions for improvement (e.g., expand educational provision, develop networking at a local level).

The last phase of the analysis was to write a report for each of the sub-themes, which was aimed at exploring the relationships between the codes. Fragments of segments were included in the reports to illustrate interpretations. Three researchers from the team revised the reports in order to detect patterns, common themes and contrasts between the data in each of the subthemes (Coffey \& Atkinson, 1996). The following section details the main results in these three sub-themes.

\section{RESULTS}

\section{Coordination between school and post-school services}

The main finding was a perceived lack of continuity between school and post-school services. Specifically, 40 of the professionals surveyed considered the support received by young people with ID on their pathway through the education system, and support offered to them after compulsory schooling, to be fragmented. 
"Throughout the education phase there is a lot of support and everything is very well-defined, very well-scheduled; they have a tutor, receive support, but then, at the time to make the leap into the labour market, they find themselves at an impasse in the sense of saying, "Okay, school has finished, now what do I do?” ... But generally it is with the young people who have been schooled in mainstream schools, who have followed the secondary curriculum, adapted to a greater or lesser extent, where there is greater discontinuity..." (Interviewee 2 VT).

One reason for this situation, according to 28 of the participants, is that in the Spanish context the organizations that usually offer support to people with ID are segregated in nature. A second reason, according to 24 of the professionals is that no suitable alternatives exist on the level of education and social policy to address the personal and professional training needs of young people with ID.

Therefore, “...there comes a time for them when there is nothing prepared. It's all a bit like applying "patches" here and there ... there's a gap between finishing all this and being able to start work... when they are still immature...” (Interviewee $4 \mathrm{SE}$ )

\section{Perceived problems in coordination between services}

There were three main problems perceived in coordination between services. Firstly, 12 participants from the post-school sphere complained that schools often do not know enough about the work they do in supporting education and labour market integration for people with ID.

As for those professionals with responsibilities in supporting transition to the school environment, none of the professionals working in special schools (SES) noted the existence of this problem, while three professionals whose role it was to support transition in 
mainstream schools (MS) acknowledged that a better understanding is required of the different alternatives at post-school level.

Furthermore, 5 professionals with responsibilities in post-school services acknowledged that an effort is required on their part to raise awareness of the work they are doing in schools:

"It's also us, we have to explain well what it is we do, how it works, we need to be informed about what they do, communicate with the schools and see on what points we can... where we can reach an agreement or do something together..." (Interviewee $5 \mathrm{SE}$ )

Secondly, difficulties were highlighted in establishing partnerships between organizations working in the same sector. This was mentioned by 11 professionals, all working in the postschool sphere, although with different responsibilities. Interviewee 5 (SW) said, "There are a lot of other things about other services I don't know. Lack of information, and if you don't know the other centres in the area, you can't inform the families properly. Communication should be more fluid, there's a need to investigate which channels of communication might be found to connect everyone in a more practical way".

Finally, it was mentioned that partnerships suffer greatly due to a lack of clear leadership in relation to the transition process. Eight professionals across the school and post-school systems highlighted this point-(4 MT, 2 SW and 2 SE). Who should assume this leadership was not broached in most of the interviews. In those interviews in which it was discussed, 7 professionals believed it is the school that should take the responsibility to lead and energize the transition process:

"The schools must organize the whole issue of guidance, the whole issue of mentoring, where there is much room for improvement." (Interviewee 1 MT) 
The professionals also identified what was hindering coordination between services. The first identified problem highlighted as affecting transition partnerships was the lack of a clear procedure for the transition process. This view was shared by 31 professionals across the school and post-school sectors. Those processes which had been established were not properly formalized and depended primarily on the willingness of individual professionals and institutions.

The second identified problem was that views regarding disability differed between services within the same sector, which made coordination and collaboration difficult. Ten professionals employed in various post-school services expressed this view:

"People don't see things the same, don't have the same view, how they see people with disability... you see very different approaches, right? And then, of course, it's very difficult to work together. And you see people saying "this is my field, after this do whatever you like, but here in my place of work I do it my way”. (Interviewee 1 IL)

Reference by 10 professionals in the post-school system was also made to services being run in an excessively rigid manner and from a medical view of disability.

The final identified problem was that the current socio-economic crisis in Spain was leading to increased competition between services rather than increased collaboration. Eleven professionals from post-school services commented that despite protests demanding the government provide the sector with sufficient resources, not enough synergies have been established to find solutions that entail coordination between services, especially if such coordination means no longer providing a particular service:

"The crisis is good for that reason, it forces us to look for synergies between services, but there is still resistance. Some things are being done, but all institutions still want to maintain 
all of their services, and do it alone ... My theory is, if there are so many services, why create another one the same? ...So we have to learn from this, right?” (Interviewee $3 \mathrm{SE}$ )

\section{Suggestions for improvement}

The participants' suggestions were influenced by the particular sector they worked in and the nature of the service they provided. However, there are some common points. Firstly, 24 participants considered that is necessary to expand educational provision in all areas for young people with ID. They agreed on measures that should be implemented to ensure the required support for people with ID in order they can access post-compulsory education as a means for social and labour inclusion. Secondly, 20 professionals pointed out the importance of promoting the local area as an element that provides a vehicle for networking initiatives. It means to explore post-school and school services operating in a local area, and implement the mechanisms that encourage the exchange of information and coordination between them.

Participants from different services highlighted the need for a change in how organizations operate to allow support to become person-centred. Eleven professionals insisted on the need to be able to focus the support provided by services and professionals on people by "working on every individual's life project”. (Interviewee 2 IL)

There were difficulties with regard to the continuity of support received by young people with ID throughout their transition process. According to the study participants, this was mainly due to the problems experienced by these young people in accessing inclusive services after finishing compulsory schooling. The following were seen as the main problems in coordinating services: professionals with responsibilities in transition not having sufficient knowledge of the alternatives available; a lack of leadership; the lack of a clear process that helps to formalize and sequence the transition actions taken by young people along their transition pathway; a diversity of views on social inclusion held by professionals and 
services; and the instability of post-school centres due to the economic crisis. The professionals suggested there was a need to expand young people's opportunities in accessing education and training options once they finish compulsory education and to foster local coordination initiatives supporting transition.

\section{Discussion}

There was consensus between professionals regarding the lack of continuity between school and post-school services. Young people with ID in Spain cannot easily access education alternatives after completing compulsory education. The services they tend to access are specially designed for adults and are mostly segregated in nature. This means that transition is especially difficult for young people coming from an inclusive school education experience. This situation was also found by Beresford (2004) and Clarke et al (2011) in UK and by Gregg (2007) in USA, who highlighted a lack of suitable options for young people, especially regarding access to training.

With regard to perceived problems in coordination between services, what stood out was the schools and services' mutual ignorance of one another. A lack of information regarding the different organizations working with people with ID, including their objectives and how they work, is one of the elements that makes it difficult to establish partnerships between professionals from different services and, consequently, also hinders guidance and support processes for young people with ID and their families when it comes to transition. This situation has been mentioned frequently in various studies aimed at analysing the transition process (Lindstrom et al, 2007; Beresford, 2004; Tarleton \& Ward, 2005).

In Spain, the period of transition to adulthood is not specifically acknowledged by social and educational policy. This means that no government protocols have been established to clearly determine which steps to follow, when to implement certain measures, or the distribution of 
responsibilities among the various services involved. Transition therefore remains in no man's land, and those transition actions that are taken depend primarily on the initiative of individual professionals at schools. In this context, a lack of clear leadership was one of the key problems perceived by the professionals interviewed in terms of coordination. In our study, the view is posited, as proposed by Rush et al (2009), that responsibility for this leadership lies with secondary schools. As an educational institution secondary school is in a unique position due to its knowledge of young people and its accessibility to families.

The professionals called for greater government involvement in planning the transition process. However, they also highlighted the role of the local area as a vehicle for implementing initiatives. There was agreement, as pointed out by Kochhar-Bryant and Greene (2009) and Kaehne and Beyer (2008b), on the need for actions at a local level involving the education, employment and social services. However, we cannot ignore the role of the economy in influencing best practices for transition (Barron \& Hassiotis, 2008; Clarke et al, 2011). In recent years, the Spanish economic crisis has led to severe cuts in social services. At particular risk are inclusive initiatives related to support for the training and labour market for people with disability. In this respect, the professionals interviewed agreed that organizations' struggle for survival is hampering any coordination between services.

Undoubtedly, the lack of institutional guidelines for the transition process makes it extremely difficult to establish collaborative work between different services. However, it was observed in our study that in many cases how the services operate hinder inter-institutional collaboration. Above and beyond coordinated work between different services, some professionals recognized the need to involve young people more directly in their transition. The lack of such participation is referred to in other studies (Barron \& Hassiotis, 2008; Beresford, 2004; Coney, 2002; Kaehne \& Beyer, 2009; Lindstrom et al, 2007). Significantly, one of the suggestions made by professionals in the present study highlights the need for a 
profound change in the organizational planning of services so as to take into account the needs, demands and expectations of young people with ID. As proposed by Cooney (2002), an improved coordination between services must not forget the need to focus processes on individuals.

\section{Conclusion}

As pointed out by Beresford (2004), the separate components of successful transition for young adults with ID (e.g., work, continuing education, personal relationships, and independence from the family) are not independent of one another. Rather, they are complex and interrelated and can only be achieved if support is established and coordinated at different levels. This requires the intervention and partnering of professionals from different service systems. In the present study, we have focused on coordination processes between services in Spain related to support for the transition of young people with ID. The opinions of professionals involved in this area lead us to identify that, of the three models of interaction agency established by Wehman et al (1988), we find ourselves in the one most removed from the partnership and collaboration that needs to take place if we are to improve transition processes.

A lack of government guidelines is one element that hinders establishment of the coordination processes necessary to ensure adequate and appropriate support for young adults with ID in their transition process. Above and beyond this recommendation, our analysis also emphasizes the need to improve communication processes between professionals, but also between them and young people and their families. In this regard, we stress the importance of providing accessible information to young adults with ID and their families, as proposed by Tarleton and Ward (2005). This condition is essential in allowing young people to fully participate in decision-making regarding their own lives. 
Finally, we must not ignore the fact that cuts in social services in Spain significantly affect the stability of inclusive projects for people with disability. Therefore, to ensure that people with ID have full opportunities to be included in educational, social and working life, the government must make a firm commitment to offer support at the different levels (ideological, legislative and budgetary) required by the projects and professionals involved in these processes.

\section{Limitations of the study}

Although the interviews were conducted with a wide range of professionals across both school and post-school sectors, the findings from this study may not be representative of the wider situation in Spain, or representative of countries with different economic and cultural backgrounds.

A further limitation is that we only talked with professionals, whereas a complete understanding of the transition process requires knowledge of the views of young adults with ID and their families.

\section{Author note}

This work was supported by the MINECO (Spanish Public Science Foundation) (grant number EDU2011-22945). The funding bodies have not imposed any restrictions on free access to or publication of the research data.

\section{Acknowledgements}

We are immensely grateful to the professionals from the different organizations who participated in our research. 
Conflict of Interest: None 


\section{References}

Act on the Social Integration of Disabled Persons (1982). Law 13/1982 of April 7th. Law on Social Integration of the Disabled. Madrid: BOE of $30^{\text {th }}$ April.

Atlas.ti Scientific Software Development (2012). Atlas.ti (v.7.0) [Software] Berlin:Germany.

Barron, A. \& Hassiotis, A. ( 2008). Good practice in transition services for Young people with LD: a review. Advances in Mental Health and Learning Disabilities, 2, 18-23. doi: 10.1108/17530180200800025

Becerra, M.T., Montanero, M. \& Lucero, M. (2012). Programas de orientación y empleo con apoyo de personas con discapacidad intelectual. Modelos y estrategias de intervención. Revista Española de Orientación y Psicopedagogía, 23(3), 9-15.

Beresford, B. (2004). On the road to nowhere? Young disabled people and transition. Child: Care, Health \& Development, 30(6), 581-7. doi: 10.1111/j.13652214.2004.00469.x

Beyer, S. \& Kaehne, A. (2008). The Transition of Young People With Learning Disabilities to Employment: What Works? Journal on Developmental Disabilities, 14(1), 85-94.

Beyer, S., Kaehne, A., Grey, J., Sheppard, K. \& Meek, A. (2008a). What works? Good practice in transition to employment for young people with learning disabilities. Cardiff: Welsh Centre for Learning Disabilities.

Beyer, S., Kaehne, A., Grey, J., Sheppard, K. \& Meek, A. (2008b). What works? Transition to employment for young people with learning disabilities. Cardiff : Welsh Centre for Learning Disabilities. 
Beyer, S., Kaehne, A., Grey, J., Sheppard, K. \& Meek, A. (2008c). What works? Transition to employment for young people with learning disabilities. Full Report. Cardiff: Welsh Centre for Learning Disabilities.

Bowen, B.A. (2008). Naturalistic inquiry and the saturation concept: A research note. Qualitative Research, 8 (1), 137-152. doi: 10.1177/1468794107085301

Clarke, S., Sloper, P., Moran, N., Cusworth, L., Franklin, A. \& Beecham, J. (2011). Multiagency transition services: greater collaboration needed to meet the priorities of Young people with complex needs as they move into adulthood. Journal of Integrated Care. 19(5), 30-40.doi: 10.1108/14769011111176734

Cobb, R.B. \& Alwell, M. (2009). Transition planning coordinating interventions for youth with disabilities. Career Developmental for Exceptional Individuals, 32(1), 70-81. Doi: 1177/0885728809336655.

Coffey, J. \& Atkinson, P.A. (1996). Making sense of Qualitative Data: complementary research strategies. London, new Delphi: Sage .

Cooney, B.F. (2002). Exploring Perspectives on Transition of Youth With Disabilities: Voices of Young Adults, Parents, and Professionals. Mental Retardation, 40(6), 42535. doi: http://dx.doi.org/10.1352/0047-6765(2002)040<0425:EPOTOY>2.0.CO;2

Foley, K-R., Dyke P., Girdler, S., Bourke, J. \& Leonard, H. (2012). Young adults with intelellectual disability transitioning from school to post-school: A literature review framed within the ICF. Disability \& Rehabilitation, 34(20): 1747-64. doi: 10.3109/09638288.2012.660603.

Gillham, B. (2005). Research interviewing. The range of techniques. Berkshire, England: Open University Press. 
Gregg, N. (2007). "Underserved and Unprepared: Postsecondary Learning Disabilities". Learning disabilities Research \& Practice, 22(4), 2019-28. doi: 10.1111/j.15405826.2007.00250.x

Hamilton, L.; Corbett-Whittier, C. (2013) Using Case Study in Education Research. London: Sage/British Educational Research Association (BERA).

Hudson, B. (2003). From adolescence to young adulthood: the partnership challenge for learning disability services in England. Disability \& Society, 18(3), 259-276. doi: $10.1080 / 0968759032000052851$.

Hudson, B. (2006). Making and missing connections: learning disability services and the transition from adolescence to adulthood. Disability \& Society, 21(1), 47-60. doi: $10.1080 / 09687590500375366$

Jordán de Urríes, F.B. \& Verdugo, M.A. (2010). Evaluation and follow up of Supported Employment Initiatives in Spain from 1995 to 2008. Journal of Vocational Rehabilitation, 33, 39-49. doi: 10.3233/JVR-2010-0514.

Kaehne, A. (2012). Partnerships in Local Government. The case of transition support services for young people with learning disabilities. Public Management Review. doi:10.1080/14719037.2012.698855

Kaehne,A. y Beyer, S. (2009). Transition partnersips: the views of education professionals and staff in support services for young people with learning disabilities. British Journal of Special Education. 36(2), 112-9. doi: 10.1111/j.1467-8578.2009.00427.x

Katsiyannis, A., Zhang, D., Woodruff, N. \& Dixon, A. (2005). Transition supports to students with mental retardation: an examination of data from the National Longitudinal 
Transition Study 2. Education and Training in Developmental Disabilities, 40, 109116.

Kochhar-Bryant, C.A. \& Greene, G. (2009). Pathways to Successful Transition for Youth with Disabilities. A Developmental Process. $2^{\text {nd }}$ Edition. Upper Saddle River: Pearson.

Lindstrom, L., Paskey, J., Dickinson, J., Doren, B., Zane, C. \& Johnson, P. (2007). Voices from the Field: Recommended Transition Strategies for Students and School Staff. The Journal for Vocational Special Needs Education, 29(2) 4-11.

LISMI (1982). Ley de Integración Social del Minusválido. Act on Social Integration of Handicapped People. Madrid: BOE of April, 20.

LOGSE (1990). General Statutory Act on the Education System. Organic Law 1/1990 of 3 October. Law on the Education System. Madrid: BOE of October, 4.

Miles, M.B. \& Huberman, A.M. (1994). Qualitative data analysis: An expanded sourcebook ( $2^{\mathrm{a}}$ ed.). Thousand Oaks, CA: Sage

Pallisera, M. (2011). Transition scenarios for young people with learning disabilities in Spain. Relationships and discrepancies. European Journal of Special Needs Education, 26 (4), 495-507. doi: 10.1080/08856257.2011.597187

Pallisera, M., Vilà, M. \& Fullana,J. (2012). Beyond school inclusion: secondary school and preparing for labour market inclusion for young people with disabilities in Spain. International Journal of Inclusive Education. 16 (11-12), 1115-1129. doi: $10.1080 / 13603116.2010 .548104$ 
Pallisera, M., Fullana, J., Martin, R. \& Vilà (2013). Transición a la vida adulta de jóvenes con discapacidad intelectual. La opinión de los profesionales de servicios escolares y postescolares. Revista Española de Orientación y Psicopedagogía. 24(2), 100-115.

Rosselló, M.R. \& Verger, S. (2008). La inclusión de personas con discapacidad en el lugar de trabajo en las Islas Baleares. Revista Europea de Formación Profesional, 45, 181200.

Rush, F.R., Hugues, C., Agran, M., Martin, J.E. \& Johnson, J.R. (2009). Toward SelfDirected Learning, Post-High School School Placement, and Coordinated Support. Constructing New Transition Bridges to Adult Life. Career Development for Exceptional Individuals, 32(1), 53-59. doi: 10.1177/0885728809332628

Saldaña, J. (2009). The Coding Manual for Qualitative Researchers. Thousand Oaks: Sage.

Tarleton, B. \& Ward, L. (2005). Changes and choice: finding out what information youg people with learning disabilities, their parents and supporters need at transition. BILD British Journal of Learning Disabilities, 33, 70-76. DOI: 10.1111/j.14683156.2005.00344.x.

Taylor, A. (2006). The challenges of partnership in school-to-work transition. Journal of Vocational Education \& Traning. 58 (3), 319-336.doi: 10.1080/13636820600955716

Wehman, P., Moon, M.S., Everson, J.M. \& Barcus, J.M. (1988). Transition from School to Work. New Challenges for Youth with Severe Disabilities. Baltimore: Paul Brookes Publishing.

Valls, M.J. \& Jové, G. (2001). El estudio de los itinerarios escolares y post-escolares como pauta de reflexión la construcción de una escuela y una sociedad para todos. Revista de Educación 325: 283-297. 
Winn, S. \& Hay, I. (2009). Transition from school for youths with a disability: Issues and Challenges. Disability \& Society, 24 (1), 103-115.doi:10.1080/09687590802535725. 


\begin{tabular}{|c|c|c|c|}
\hline \multicolumn{2}{|c|}{$\begin{array}{r}\text { Field } \\
\end{array}$} & \multirow{2}{*}{$\begin{array}{l}\text { Specific roles/responsibilities } \\
\text { Organization of educational } \\
\text { activities related to transition }\end{array}$} & \multirow{2}{*}{$\begin{array}{c}\text { Number of } \\
\text { participants } \\
8\end{array}$} \\
\hline $\begin{array}{l}\text { School } \\
\text { system }\end{array}$ & $\begin{array}{l}\text { SES: Special Education } \\
\text { Schools }\end{array}$ & & \\
\hline & $\begin{array}{l}\text { MS: teachers at } \\
\text { mainstream schools }\end{array}$ & $\begin{array}{l}\text { Coordination of educational } \\
\text { projects related to transition }\end{array}$ & 9 \\
\hline & $\begin{array}{l}\text { MT: members of multi- } \\
\text { professional teams (teams } \\
\text { external to schools, } \\
\text { responsible for a given } \\
\text { geographical area) }\end{array}$ & $\begin{array}{l}\text { Guidance for young people } \\
\text { with disabilities and } \\
\text { professionals throughout the } \\
\text { educational process }\end{array}$ & 10 \\
\hline \multicolumn{3}{|c|}{ Total participants in educational sphere } & 27 \\
\hline \multirow[t]{3}{*}{$\begin{array}{l}\text { Post- } \\
\text { school } \\
\text { sphere }\end{array}$} & $\begin{array}{l}\text { SW: professionals from } \\
\text { sheltered workshops }\end{array}$ & $\begin{array}{l}\text { Coordination of post-school } \\
\text { projects and services } \\
\text { (Occupational Centres or } \\
\text { Special Work Centres) }\end{array}$ & 6 \\
\hline & $\begin{array}{l}\text { SE: Supported } \\
\text { employment services }\end{array}$ & $\begin{array}{l}\text { Organization of labour market } \\
\text { integration projects }\end{array}$ & 7 \\
\hline & $\begin{array}{l}\text { VT: participants working } \\
\text { on projects aimed at } \\
\text { vocational training }\end{array}$ & $\begin{array}{l}\text { Organization of vocational } \\
\text { training actions }\end{array}$ & 3 \\
\hline
\end{tabular}




\begin{tabular}{|l|l|l|c|}
\hline & $\begin{array}{l}\text { IL: professionals } \\
\text { providing support for } \\
\text { independent living }\end{array}$ & projects for independent living & \\
& & \\
\hline \multicolumn{2}{|l|}{ Total participants in the post-school sphere } & $\mathbf{1 8}$ \\
\hline Total participants & $\mathbf{4 5}$ \\
\hline
\end{tabular}

Table 1: Participants: distribution according to service and responsibilities 